\title{
Anticentromere antibodies in subjects with no apparent connective tissue disease
}

\author{
Shu-Ling Lee, Gregory J Tsay, Rong-Tai Tsai
}

\begin{abstract}
Objectives-To study the association of anticentromere antibodies (ACA) in various diseases.

Methods-A total of 4800 consecutive serum samples were tested for ACA by indirect immunofluorescence using HEp2 cells as substrates and by immunoblotting of Molt-4 cell mitotic chromosomal antigens and recombinant CENP-B protein.
\end{abstract}

Results-Anticentromere antibodies were identified in the serum samples of 24 subjects, including eight without apparent connective tissue diseases, six with primary biliary cirrhosis, two with diffuse scleroderma, one with pulmonary hypertension, one with primary Raynaud's phenomenon, one with CREST syndrome (calcinosis, Raynaud's phenomenon, oesophageal dysmotility, sclerodactyly, telangiectasia), and five with other connective tissue diseases. By immunoblotting using Molt-4 cells mitotic chromosomal antigens three centromere antigens were recognised by these serum samples. These were: CENP-A (17 kilodalton recognised by 22 of 24 ACA positive serum samples); CENP-B (80 kilodalton recognised by 22 of 24 ACA positive serum samples); and CENP-C (140 kilodalton recognised by 19 of 24 ACA positive serum samples). There was no specific pattern for serum samples from patients with different groups of diseases on immunoblotting. Recombinant CENP$B$ proteins were all recognised by these samples. Patients without apparent connective tissue disease often had a lower ACA titre than patients with primary biliary cirrhosis.

Conclusions-These data suggest that a positive result for ACA does not always indicate the presence of a connective tissue disease.

(Ann Rheum Dis 1993; 52: 586-589)

Medicine,

Chung Shan Medical

and Dental College,

Taichung, Taiwan

S-L Lee

G J Tsay

R-T Tsai

Correspondence to:

Dr G J Tsay,

Department of Medicine Chung Shan Medical and Dental College,

23 Section 1 ,

Taichung Kang Road,

Taichung, Taiwan,

Republic of China.

Accepted for publication 20 April 1993 phageal dysmotility, sclerodactyly, telangiectasia), ${ }^{1}$ diffuse systemic sclerosis, ${ }^{2}$ primary biliary cirrhosis, ${ }^{3}$ and other connective tissue diseases. ${ }^{4}$ It is generally accepted that there is a strong correlation between ACA and Raynaud's phenomenon, ${ }^{4}$ and ACA often identify patients with less severe disease. ${ }^{25}$ In this study we investigated the clinical correlates of ACA and attempted to determine whether or not a special pattern of these chromosomal antigens recognised by serum samples from different groups of patients could be established by immunoblotting. We also evaluated the significance of titres of ACA in various diseases.

\section{Subjects and methods}

PATIENTS

The serum samples used for this study were from 24 patients positive for ACA as determined by indirect immunofluorescence. These serum samples were found among 4800 samples submitted during four years of antinuclear antibody testing. Patients were followed up at Chung Shan Medical and Dental College Hospital and in local clinics around Taichung, Taiwan. All patients positive for ACA were examined by a member of the rheumatology faculty at the hospital and patients taking drugs such as D-penicillamine known to induce ACA were excluded.

The diagnosis of Raynaud's phenomenon was based on a typical history and on plethysmographic patterns during cold provocation or warming, or both. Suspected secondary Raynaud's phenomenon was diagnosed when a patient showed a few symptoms of a connective tissue disease but without all the criteria necessary for a definite diagnosis. ${ }^{4}$ The criteria for diagnosis of primary biliary cirrhosis were accepted clinical and histological criteria. ${ }^{6}$ Scleroderma was identified according to the preliminary criteria for the diagnosis of systemic sclerosis. ${ }^{7}$ Patients were grouped as having no apparent connective tissue disease when none of the signs nor symptoms of connective tissue diseases were present and laboratory tests for erythrocyte sedimentation rate, rheumatoid factor, $\mathrm{C}$ reactive protein, and blood count were normal. In all patients with ACA a careful history and physical examination were performed with special attention to signs and symptoms of connective tissue disease such as arthralgia, arthritis, Raynaud's phenomenon, sclerodactyly, proximal scleroderma, telangiectasia, dysphagia, pulmonary symptoms, mouth ulcers, digital scars or loss of finger pad substance, and calcinosis, photosensitivity, and skin rash.
INDIRECT IMMUNOFLUORESCENCE

Anticentromere antibodies and antinuclear antibodies were detected by indirect 
immunofluorescence using HEp-2 cells (Antibodies Inc, Davis, CA, USA) as described previously. ${ }^{12}$ Each serum sample was screened for the presence of ACA at a 1:80 dilution and further serial fourfold dilutions were performed if the sample was positive for ACA. Anticentromere antibodies were considered to be present in interphase cells by typical discrete speckled staining and by characteristic localisation in mitotic cells. ${ }^{1}$ Immunoglobulin isotypes and the IgG subclass of ACA were also determined by indirect immunofluoresence with fluorescein conjugated goat antihuman IgG, IgM, and IgA (Behringwerke, Marburg, Germany) for immunoglobulin isotypes and fluorescein conjugated monoclonal antihuman IgG subclass (Sigma Chemical, St Louis, MO, USA) for IgG subclasses. ${ }^{8}$

PREPARATION OF CENTROMERE ANTIGENS Molt-4 cells (human $\mathrm{T}$ cell lymphoblastic leukaemia) were maintained in suspension culture at $37^{\circ} \mathrm{C}$ with S-MEM supplemented with $10 \%$ heat inactivated fetal calf serum (Gibco, Grand Island, NY, USA), $100 \mathrm{U} / \mathrm{ml}$ penicillin, $100 \mu \mathrm{g} / \mathrm{ml}$ streptomycin, and 20 $\mathrm{mmol} / \mathrm{l} \mathrm{L}$-glutamine. The cells were blocked in metaphase with $0.1 \mu \mathrm{g} / \mathrm{ml}$ colcemid overnight. Mitotic cells were harvested by centrifugation at $1000 \mathrm{rev} / \mathrm{min}$ for 10 minutes and washed twice with cold $\left(4^{\circ} \mathrm{C}\right)$ phosphate buffered saline (PBS); the cells were resuspended to swell in RSB buffer (10 mM TRIS- $\mathrm{HCl} \mathrm{pH}$ $7 \cdot 4,10 \mathrm{mM} \mathrm{NaCl}, 5 \mathrm{mM} \mathrm{MgCl}$ ) containing $0 \cdot 1 \%$ Triton X-100 for 30 minutes on ice. All buffers contained $1 \mathrm{mM}$ phenylmethylsulphonyfluoride (Sigma Chemical) to inhibit proteases. The cells were homogenised in a tight fitting glass homogeniser until the cell membranes were broken, as assessed by examination under a phase contrast light microscope. Nuclei were spun down at 800 $\mathrm{rev} / \mathrm{min}$ for 10 minutes, washed twice in RSB buffer, and resuspended in $1 \mathrm{mM} \mathrm{Na}_{3} \mathrm{PO}_{4}, \mathrm{pH}$ $7 \cdot 0$. The suspension was sonicated at least 10 times for 10 seconds until all the nuclei had disintegrated as determined by a phase contrast light microscope. The insoluble material was removed by centrifugation at $10000 \mathrm{rev} / \mathrm{min}$ for 15 minutes at $4^{\circ} \mathrm{C}$ and the supernatant was collected and stored at $-70^{\circ} \mathrm{C}$ until use.

\section{IMMUNOBLOTTING}

Sodium dodecyl sulphate polyacrylamide gel electrophoresis (SDS-PAGE) using a $15 \%$ acrylamide slab gel was performed according to the method of Laemmli. ${ }^{9}$ Samples were reduced for two minutes in boiling water with $0.0625 \mathrm{M}$ TRIS- $\mathrm{HCl}$ buffer, $\mathrm{pH} 6.8$, containing $2.3 \%$ SDS, $5 \% 2$-mercaptoethanol, and $10 \%$ glycerol. Samples applied to the gel were run at $100-150 \mathrm{~V}$ for five hours. They were then electrophoretically transferred to a nitrocellulose filter according to the method of Towbin et al. ${ }^{10}$ The nitrocellulose filters were cut into strips and soaked in $2 \%$ non-fat dry milk in PBS for one hour at room temperature to saturate irrelevant protein binding sites.
Antisera diluted 1/100 with 3\% non-fat dry milk in PBS were reacted with the nitrocellulose strips and incubated for one hour; bound antibody was detected by autoradiography after a one hour incubation with protein A labelled with iodine-125. Student's $t$ test was used for statistical analysis.

\section{Results}

Twenty four serum samples were positive for ACA by indirect immunofluoresence on HEp2 cells. Figure 1 gives the clinical diagnosis and titres of ACA of the 24 patients with positive results. There were three men and 21 women aged from 35 to 82 years with a mean (SD) age of $61.54(11.51)$ years. Of the 24 patients positive for ACA eight had no apparent connective tissue disease, six had primary biliary cirrhosis, two had systemic sclerosis, one had CREST syndrome, one had primary Raynaud's phenomenon, five had suspected secondary Raynaud's phenomenon, and one had pulmonary hypertension. The titres of ACA were significantly higher in patients with primary biliary cirrhosis than in patients without apparent connective tissue disease $(\mathrm{p}<0 \cdot 05)$.

The distribution of immunoglobulin isotypes of ACA in different groups of patients was studied. IgG was present in all patients with ACA. IgM and IgA were less often present in these serum samples. Not all patients with primary biliary cirrhosis had IgM. The IgG subclasses were largely restricted to IgG1 and IgG3. The IgG1 subclass was found in 12 of 24 serum samples positive for ACA. IgG3 was present in four of 24 serum samples positive for ACA. There was no IgG2 and IgG4 in serum samples positive for ACA.

The table gives the clinical diagnosis of the eight patients without signs and symptoms of connective tissue disease. Anticentromere antibodies were accidentally found in these patients. All patients had various long term medical disorders not relating to connective tissue diseases, which included chronic dermatitis, valvular heart disease, chronic headache, cataract, polycystic kidney,



Figure 1 Mean titre of anticentromere antibodies ( $A C A$ ) in different groups of diseases. The titre of $A C A$ was determined by indirect immunofluorescence on HEp-2 cells. $N C T D=$ subjects with no apparent connective tissue disease; $P B C=$ primary biliary cirrhosis; $S S c=$ systemic sclerosis; CREST = calcinosis, Raynaud's phenomenon, oesophageal dysmotility, sclerodatyly, and telangiectasia; $P R P=$ primary Raynaud's phenomenon; $S S R P=$ suspected secondary Raynaud's phenomenon; $P H=$ pulmonary hypertension. 
Summary of clinical data of subjects with no apparent connective disease

\begin{tabular}{lll}
\hline $\begin{array}{l}\text { Patient } \\
\text { No }\end{array}$ & $\begin{array}{l}\text { Sex/age } \\
\text { (years) }\end{array}$ & Clinical features \\
\hline 1 & F/61 & $\begin{array}{l}\text { Chronic dermatitis } \\
\text { Valvular heart disease }\end{array}$ \\
2 & M/54 & Chronic headache \\
4 & F/43 & Cataract \\
5 & F $/ 67$ & Polycystic kidney \\
6 & F $/ 55$ & Chronic headache \\
7 & F/67 & $\begin{array}{l}\text { Mother of an infant with congenital } \\
\text { heart block }\end{array}$ \\
8 & F/35 & Gallstones \\
\hline
\end{tabular}

gallstones, and one was the healthy mother of an infant with congenital heart block. It is of interest to note that serum from patient 7 was accidentally found to contain ACA because she gave birth to a daughter with congenital heart block. Their serum samples did not contain any other known antibodies including antibodies to Ro/SS-A, La/SS-B, and RNP by immunoblotting.

Using a Molt-4 whole nuclei sonicate as the source of antigen for immunoblotting, ACA binding to 17 kilodalton (CENP-A), 80 kilodalton (CENP-B), and 140 kilodalton (CENP-C) antigens were observed (fig 2). Lane 1 shows a normal control serum. Lanes 2-4 were serum samples with ACA from patients with suspected secondary Raynaud's phenomenon. Lanes 5 and 6 were from patients with primary biliary cirrhosis with

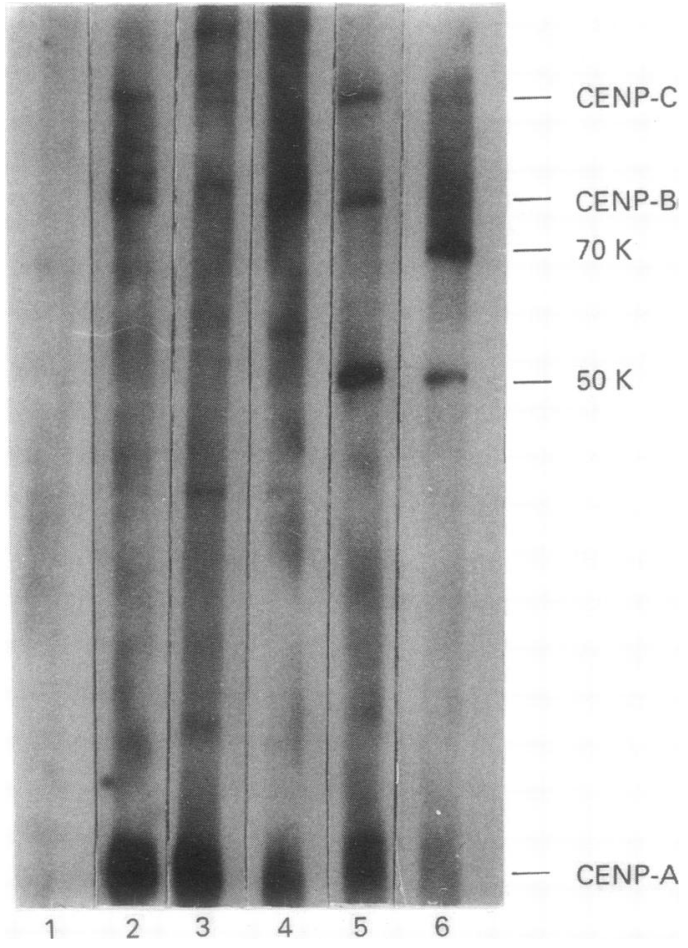

Figure 2 Immunoblot patterns of serum samples. Protein of isolated Molt-4 chromosomes were separated by sodium dodecyl sulphate/polyacrylamide gel electrophoresis and electrophoretically transferred to nitrocellulose. Immunoblots of chromosmal proteins were probed with normal control serum (lane 1), serum samples with anticentromere antibodies from patients with suspected secondary

Raynaud's phenomenon (lanes 2-4), and serum samples with anticentromere antibodies from patients with primary biliary cirrhosis (lanes 5 and 6). CENP-A, CENP-B, and $C E N P-C$ proteins are shown on the right. Serum samples from patients with primary biliary cirrhosis also react with 50 and 70 kilodalton proteins of mitochondrial antigens in addition to $C E N P-A, C E N P-B$, and $C E N P-C$.
ACA which reacted with 50 and 70 kilodalton proteins of mitochondrial antigens in addition to CENP-A, CENP-B, and CENP-C. Most serum samples positive for ACA recognised CENP-A protein $(92 \%)$, CENP-B protein $(92 \%)$, and CENP-C protein $(79 \%)$. All 24 serum samples positive for ACA also recognised recombinant CENP-B protein by immunoblotting (data not shown).

\section{Discussion}

In this study, $8 / 24$ or $33 \%$ of patients with ACA did not have any symptoms or signs of connective tissue disease. The patients were accidentally identified by antinuclear antibody screening at the hospital. They had multiple somatic disorders and had not taken drugs such as D-penicillamine known to induce ACA. This is the first study showing the highest prevalence of ACA in patients without rheumatic diseases. In contrast, most studies have shown that ACA are present primarily in patients with CREST syndrome and are strongly correlated with Raynaud's phenomenon. ${ }^{124}$ The evolution of these patients without apparent connective tissue disease with positive ACA is unknown. These patients usually have relatively lower titres of ACA. Low titres of ACA have been reported in first and second degree relatives of patients with CREST syndrome in the absence of Raynaud's phenomenon. ${ }^{11}$ Wade et al also reported two of 49 patients with ACA not associated with any symptoms or signs of connective tissue disease. ${ }^{12}$ It is not known whether our patients will develop overt rheumatic disease in the future. At present we cannot explain the significance of the occurrence of ACA in this group of patients.

Anticentromere antibodies were detected in six of $24(25 \%)$ patients with primary biliary cirrhosis in this study. This is consistent with reports by other workers who have noted ACA in patients with primary biliary cirrhosis. ${ }^{3}$ This antibody seems to be another important autoantibody in addition to antimitochondrial antibodies in patients with primary biliary cirrhosis. Patients with primary biliary cirrhosis have the highest titres of ACA which are restricted to IgG only (fig 1 ). All these patients with primary biliary cirrhosis had at least one feature of scleroderma. A high titre of ACA has been reported to be associated with thrombotic vascular disease. ${ }^{13}$

We found that most ACA were of the IgG isotype and largely restricted to the $\operatorname{IgG} 1$ and IgG3 subclasses. These results are in good agreement with those of French and Bernstein. ${ }^{8}$ Several reports have shown that IgG1 and IgG3 are the predominant subclasses of antibodies to Sm, RNP, histone, SS-B/La, dsDNA, and ssDNA in patients with systemic lupus erythematosus, Sjögren's syndrome, and drug induced autoimmunity. ${ }^{14}$ As IgG1 and IgG3 are linked to immune responses dependent on $T$ cells, the predominant subclasses of IgG1 and IgG3 displayed by these autoantibodies and ACA may indicate that a common immunological feature of 
autoantigens or a common control mechanism underlies the regulation of autoantibody expression in these autoimmune diseases.

Three centromere autoantigens were recognised by our serum samples positive for ACA at a frequency similar to other reports. ${ }^{15}$ There was no specific pattern of centromere antigens distinguishing the patient groups on immunoblotting. Recombinant CENP-B protein was recognised by all serum samples positive for ACA. This is consistent with the report of Earnshaw et al that CENP-B is a major centromere autoantigen. ${ }^{15}$

Our study confirms that ACA can be found in a variety of connective tissue diseases and also in patients without apparent connective tissue disease. In this group the titre of ACA tends to be lower.

This study was partly supported by grant NSC 81-0412-B040-502 from National Science Council, Taiwan. Recombinant CENP-B protein was kindly supplied by Dr Kevin F Sullivan, The Scripps Research Institute, La Jolla, CA, USA.

1 Moroi Y, Peebles C, Fritzler M F, Steigerwald J, Tan E M. Autoantibody to centromere (kinetochore) in scleroderma sera. Proc Natl Acad Sci USA 1980; 77: 1627-31.

2 Tan E M, Rodana G P, Garcia I, Moroi Y, Fritzler M J, Peebles C. Diversity of antinuclear antibodies in progressive systemic sclerosis: anti-centromere antibody and its relationship to CREST syndrome. Arthritis Rheum 1980; 23: 617-25.

3 Bernstein $R$ M, Callender $M$ E, Neuberger J M, Hughes C R V, Williams R. Anticentromere antibody in primary biliary cirrhosis. Ann Rheum Dis 1982; 41: primary
4 Kallenberg C G M, Pastoor G W, Wouda A A, The T H. Antinuclear antibodies in patients with Raynaud's phenomenon: clinical significance of anticentromere antibodies. Ann Rheum Dis 1982; 41: 382-7.

5 Fritzler M J, Kinsella T D, Garbutt E. The CREST syndrome: a distinct serologic entity with anticentromere antibodies. Am F Med 1980; 69: 520-6.

6 Williamson J M, Chalmers D M, Clayden A D, Digxon M F, Ruddell W S, Losowsky M S. Primary biliary cirrhosis and chronic active hepatitis: an examination of clinical biochemical, and histopathological features in differential diagnosis. $f$ Clin pathological features in

7 Subcommittee for Scleroderma Criteria of the American Rheumatism Association Diagnostic and Therapeutic Criteria Committee. Preliminary criteria for the classification of systemic sclerosis (scleroderma). Arthritis Rheum 1980; 23: 581-90.

8 French M A H, Bernstein R M. Immunoglobulin G subclass distribution of autoantibodies in systemic sclerosis, primary biliary cirrhosis, and overlap syndromes. Ann Rheum Dis 1987; 46: 436-40.

9 Laemmli U K. Cleavage of structural proteins during the assembly of the head of bacteriophage T4. Nature 1970; 227: $680-5$.

10 Towbin H, Stachelin T, Gordon J. Electrophoretic transfer of proteins from polyacrylamide gels to nitrocellulose sheets: procedure and some applications. Proc Natl Acad Sheets: procedure and some

11 Ruffatti A, Artifoni L, Glorioso S, et al. Prevalence of anticentromere antibody in blood relatives of anticentroanticentromere antibody in blood relatives of anticen

12 Wade J P, Sack B, Schur P H. Anticentromere antibodiesclinical correlates. F Rheumatol 1988; 15: 1759-63.

13 Buchanan R R C, Riglar A G. The titre of anti-centromere antibodies: its relationship to Raynaud's phenomenon and vascular occlusion. Brf Rheumatol 1989; 28: 221-6.

14 Rubin R L, Tang F, Chan E K L, Pollard K M, Tsay G J, Tan E M. IgG subclasses of autoantibodies in systemic lupus erythematosus, Sjogren's syndrome, and drug-induced autoimmunity. F Immunol 1986; 137: 2528-34.

15 Earnshaw W C, Bordwell B, Marino C, Rothfield N. Three human chromosomal autoantigens are recognised by sera from patients with anti-centromere antibodies. $尹$ Clin Invest 1986; 77: 426-30. 